Check for updates

Cite this: Mater. Adv., 2021,

2, 996

\title{
Molecular structure controlled self-assembly of pyridine appended fluorophores: multi-stimuli fluorescence responses and fabricating rewritable/ self-erasable fluorescent platforms $\dagger$
}

\author{
Parthasarathy Gayathri, ${ }^{a}$ Mehboobali Pannipara, ${ }^{\text {bc }}$ Abdullah G. Al-Sehemi, ${ }^{\text {bc }}$ \\ Dohyun Moon (D) *d and Savarimuthu Philip Anthony (D)*a
}

\begin{abstract}
The fluorescence properties of organic materials are intrinsically governed by the molecular conformation and intermolecular interaction mediated aggregation. Herein, we have synthesized two sets of isomeric fluorescence molecules with a partially planar and propeller structure, (Z)-3-(4-(9H-carbazol-9-yl)phenyl)2-(pyridinyl)acrylonitrile (1-3) and (Z)-3-(4-(diphenylamino)phenyl)-2-(pyridinyl)acrylonitrile (4-6) and explored their effect on the molecular aggregation, and tunable and switchable solid state fluorescence. Molecular aggregation studies revealed the formation of 1D nanostructures of nanoparticles with the evolution of intermolecular interactions with increasing water fraction and time. The evolution of nanostructures led to a tunable fluorescence from green to red. The subtle structural change and formation of different crystal forms/ polymorphs resulted in a tunable fluorescence between 514 and $644 \mathrm{~nm}\left(\Phi_{\mathrm{f}}=11.3\right.$ to $\left.25.3 \%\right)$. Solid state structural studies showed relatively weak intermolecular interactions in the crystal lattice of $\mathbf{1} \mathbf{3}$ and $\mathbf{6}$ that resulted in the formation of different crystal forms/polymorphs and varied molecular assemblies with tunable fluorescence. Mechanofluorochromism (MFC) studies also showed molecular structure dependent fluorescence switching. 1-3 and $\mathbf{6}$ showed crushing/heating induced reversible fluorescence switching whereas $\mathbf{4}$ and $\mathbf{5}$ did not show any MFC. Integrating an acid/base sensitive pyridine functionality has been exploited for demonstrating halochromic reversible fluorescence switching as well as fabricating rewritable/self-erasable fluorescent platforms on filter paper and glass plates.
\end{abstract}

Received 25th September 2020 Accepted 10th December 2020

DOI: 10.1039/d0ma00736f

rsc.li/materials-advances molecular self-assembly and stimuli induced molecular packing alterations. $^{12-19}$ Non-planar flexible structures produced tunable fluorescent polymorphs via conformational freedom. ${ }^{16-19}$ Moreover, twisted non-planar molecular conformations with weak intermolecular interactions exhibited drastic fluorescence colour changes due to the transformation of molecular packing, phase, conformation and excited state (locally excited state to chargetransfer state, triplet to singlet state or monomer to excimer state) upon applying mechanical pressure. ${ }^{20-29}$ Subtle molecular change often produced remarkable fluorescence modulation and molecular aggregation. ${ }^{30-32}$ Anthracene functionalized triphenylethylene fluorophores exhibited a rare two sequential fluorescence switching initiated by one stimulus via forming an anthracene excimer intermediate. $^{33}$ Integrating anthracene with tetraphenylethylene (TPE) showed pressure induced enhanced blue shifted fluorescence by suppression of energy transfer. ${ }^{34}$ TPE based donor (D)-acceptor (A) materials showed a molecular structure dependent pressure induced fluorescence enhancement. ${ }^{9,29,35-39}$ Introducing alkyl chains resulted in self-reversible MFC materials and supercooled fluorescent liquids. ${ }^{40-42}$ Triphenylamine (TPA) based D-A-D molecules with pyridine units showed remarkable fluorescence 


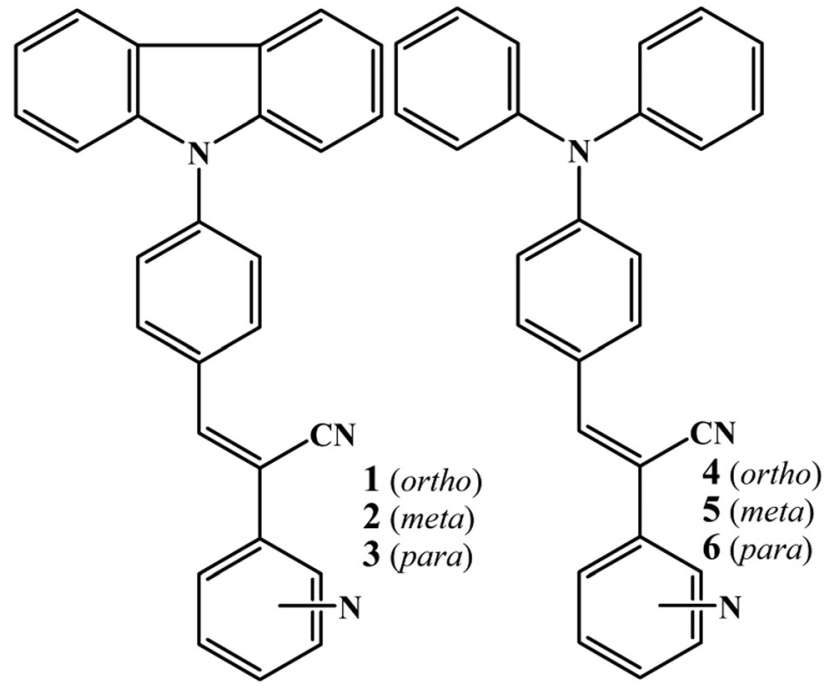

Scheme 1 Molecular structure of 1-6

switching. ${ }^{43}$ Integrating acid responsive pyridine units leads to halochromic fluorescence switching. ${ }^{14,44-48}$ Halochromic isoquinoline functionalized mechanochromic TPA has been employed for fabricating rewritable fluorescent platforms. ${ }^{49}$ Nevertheless, the versatility of small molecules to exhibit varied molecular assembly and functions via delicately controlled conformation and supramolecular interactions continues to attract great interest.

Herein, we have synthesized two sets of positional isomers (Scheme 1, 1-6) that differ subtly in the structure to explore their impact on the molecular assembly and switchable and tunable fluorescence. Interestingly, the subtle structural change drastically influenced the formation of nanostructures, solid state fluorescence and mechanofluorochromism (MFC). Carbazole based isomers (1-3) produced multiple crystal forms/polymorphs with tunable fluorescence between 514 and $644 \mathrm{~nm}\left(\Phi_{\mathrm{f}}=11.3\right.$ to $\left.25.3 \%\right)$. The fluorescent crystals and nanostructure evolution are controlled by supramolecular interactions that varied with the molecular structure. The presence of the nitrogen functionality allowed demonstrating halochromic fluorescence switching via exposing trifluoroacetic acid (TFA) and $\mathrm{NH}_{3}$. The structure dependent response has been exploited for fabricating rewritable and self-erasable fluorescent platforms.

\section{Experimental section}

Carbazole, CuI, 18-crown-6, triphenylamine, 2-pyridylacetonitrile, 3pyridylacetonitrile, 4-pyridylacetonitrile, $\mathrm{K}_{2} \mathrm{CO}_{3}$, and sodium methoxide were purchased from Sigma-Aldrich and used without further purification. 4-(9H-Carbazol-9-yl) benzaldehyde and 4-(diphenylamino) benzaldehyde were synthesized by following the reported procedure. $^{50,51}$

\section{General procedure for synthesizing 1-6 (Scheme S1, ESI $†$ )}

4-(9H-Carbazol-9-yl) benzaldehyde/4-diphenylamine benzaldehyde (1.0 equivalent) was dissolved in methanol and stirred at room temperature. To this solution, pyridine substituted phenylacetonitrile (1.5 equivalents) and sodium methoxide ( 2 equivalents) were added and the reaction mixture was stirred at $60{ }^{\circ} \mathrm{C}$ for $2 \mathrm{~h}$. Finally, the reaction mixture was cooled to room temperature and the product was filtered and washed with cold methanol.

(Z)-3-(4-(9H-Carbazol-9-yl)phenyl)-2-(pyridine-2-yl)acrylonitrile (1). Yield: $79 \%$. M.p.: $162-164{ }^{\circ} \mathrm{C}$. IR $\left(\mathrm{KBr}, \mathrm{cm}^{-1}\right): 3418(\mathrm{~N}-\mathrm{H})$, $3048(\mathrm{C}-\mathrm{H}), 2215(\mathrm{C} \equiv \mathrm{N}), 1591$ (aromatic $\mathrm{C}=\mathrm{C}), 1450(\mathrm{C}-\mathrm{H}$ double bond), $745(\mathrm{CH}) .{ }^{1} \mathrm{H}$ NMR $\left(300 \mathrm{MHz}, \mathrm{CDCl}_{3}\right) \delta 8.69-8.67$ (d, 1H), 8.59 (s, 1H), 8.26-8.23 (d, 2H), 8.16-8.13 (d, 2H), 7.86$7.82(\mathrm{~m}, 2 \mathrm{H}), 7.80-7.72(\mathrm{~d}, 2 \mathrm{H}), 7.55-7.47$ (d, 2H), 7.46-7.41 $(\mathrm{m}, 2 \mathrm{H}), 7.35-7.29(\mathrm{~m}, 3 \mathrm{H}) .{ }^{13} \mathrm{C}$ NMR $\left(75 \mathrm{MHz}, \mathrm{CDCl}_{3}\right) \delta 150.94$, $149.75,143.87,140.26,140.20,137.52,131.96,131.58,126.90$, $126.23,123.83,123.71,121.45,120.59,120.47,117.88,110.38$, 109.92. $\mathrm{C}_{26} \mathrm{H}_{17} \mathrm{~N}_{3}$ (371.14): calculated. C 84.07, $\mathrm{H} 4.61, \mathrm{~N} 11.31$; found C 84.16, $\mathrm{H}$ 4.66, $\mathrm{N}$ 11.12. $\mathrm{m} / \mathrm{z}$ calculated for $\mathrm{C}_{26} \mathrm{H}_{17} \mathrm{~N}_{3}(\mathrm{M}+\mathrm{H})$ : 371.14, found: 371.2 .

(Z)-3-(4-(9H-Carbazol-9-yl)phenyl)-2-(pyridine-3-yl)acrylonitrile (2). Yield: $85 \%$. M.p.: $149-151{ }^{\circ} \mathrm{C}$. IR $\left(\mathrm{KBr}, \mathrm{cm}^{-1}\right): 3419(\mathrm{~N}-\mathrm{H})$, $3055(\mathrm{C}-\mathrm{H}), 2224(\mathrm{C} \equiv \mathrm{N}), 1595$ (aromatic $\mathrm{C}=\mathrm{C}), 1449(\mathrm{C}-\mathrm{H}$ double bond), $748(\mathrm{CH}) .{ }^{1} \mathrm{H}$ NMR $\left(300 \mathrm{MHz}, \mathrm{CDCl}_{3}\right) \delta 8.99$ (s, 1H), 8.68-8.67 (d, 1H), 8.18-8.14 (t, 4H), 8.03-8.01 (d, 1H), 7.76-7.74 (d, 2H), $7.67(\mathrm{~s}, 1 \mathrm{H}), 7.53-7.51(\mathrm{~d}, 2 \mathrm{H}), 7.46-7.42$ (m, 3H), 7.34-7.31 (s, 2H). ${ }^{13} \mathrm{C}$ NMR $\left(75 \mathrm{MHz}, \mathrm{CDCl}_{3}\right) \delta 150.22$, 147.06, 142.52, 140.26, 140.23, 133.57, 131.75, 131.10, 130.52, $127.01,126.25,123.84,123.76,120.65,120.50,117.25,109.82$, 108.75. $\mathrm{C}_{26} \mathrm{H}_{17} \mathrm{~N}_{3}$ (371.14): calculated. C 84.07, H 4.61, N 11.31; found $\mathrm{C} 84.12, \mathrm{H} 4.51, \mathrm{~N} 11.22 . \mathrm{m} / z$ calculated for $\mathrm{C}_{26} \mathrm{H}_{17} \mathrm{~N}_{3}(\mathrm{M}+\mathrm{H})$ : 371.14, found: 371.2 .

(Z)-3-(4-(9H-Carbazol-9-yl)phenyl)-2-(pyridine-4-yl)acrylonitrile (3). Yield: $87 \%$. M.p.: $165-168{ }^{\circ} \mathrm{C}$. IR $\left(\mathrm{KBr}, \mathrm{cm}^{-1}\right): 3432(\mathrm{~N}-\mathrm{H})$, $3046(\mathrm{C}-\mathrm{H}), 2217(\mathrm{C} \equiv \mathrm{N}), 1592$ (aromatic $\mathrm{C}=\mathrm{C}), 1450(\mathrm{C}-\mathrm{H}$ double bond), $752(\mathrm{CH}) .{ }^{1} \mathrm{H}$ NMR $\left(300 \mathrm{MHz}, \mathrm{CDCl}_{3}\right) \delta 8.75-8.73$ (dd, 2H), 8.21-8.18 (d, 2H), 8.17-8.14 (d, 2H), 7.81-7.75 (m, 3H), 7.63-7.61 (m, 2H), 7.54-7.51 (d, 2H), 7.47-7.42 (m, 2H), 7.36-7.25 $(\mathrm{m}, 2 \mathrm{H}) .{ }^{13} \mathrm{C}$ NMR $\left(75 \mathrm{MHz}, \mathrm{CDCl}_{3}\right) \delta 150.75,143.79,141.65$, $140.74,140.15,131.45,131.28,126.99,126.28,123.91,120.74$, 120.53, 119.98, 116.97, 109.82, 109.50. $\mathrm{C}_{26} \mathrm{H}_{17} \mathrm{~N}_{3}$ (371.14): calculated. C 84.07, H 4.61, N 11.31; found C 84.20, H 4.58, N 11.42. m/z calculated for $\mathrm{C}_{26} \mathrm{H}_{17} \mathrm{~N}_{3}(\mathrm{M}+\mathrm{H})$ : 371.14, found: 371.2.

(Z)-3-(4-(Diphenylamino)phenyl)-2-(pyridine-2-yl)acrylonitrile (4). Yield: $86 \%$. M.p.: $141-143{ }^{\circ} \mathrm{C}$. IR $\left(\mathrm{KBr}, \mathrm{cm}^{-1}\right): 3425(\mathrm{~N}-\mathrm{H})$, $3056(\mathrm{C}-\mathrm{H}), 2210(\mathrm{C} \equiv \mathrm{N}), 1581$ (aromatic $\mathrm{C}=\mathrm{C}), 1491(\mathrm{C}-\mathrm{H}$ double bond), $697(\mathrm{CH}) .{ }^{1} \mathrm{H}$ NMR $\left(300 \mathrm{MHz}, \mathrm{CDCl}_{3}\right) \delta 8.61-8.60$ $(\mathrm{d}, 1 \mathrm{H}), 8.35(\mathrm{~s}, 1 \mathrm{H}), 7.88-7.77(\mathrm{~d}, 2 \mathrm{H}), 7.75-7.70(\mathrm{~m}, 2 \mathrm{H}), 7.34-$ $7.30(\mathrm{t}, 4 \mathrm{H}), 7.22-7.21(\mathrm{~m}, 1 \mathrm{H}), 7.18-7.16(\mathrm{~m}, 5 \mathrm{H}), 7.13-7.12$ $(\mathrm{m}, 1 \mathrm{H}), 7.05-7.03(\mathrm{~d}, 2 \mathrm{H}) .{ }^{13} \mathrm{C} \mathrm{NMR}\left(75 \mathrm{MHz}, \mathrm{CDCl}_{3}\right) \delta 151.84$, 150.56, 149.50, 146.44, 144.51, 137.29, 131.57, 129.63, 125.95, 125.84, 124.63, 122.79, 120.86, 120.41, 118.74, 105.89. $\mathrm{C}_{26} \mathrm{H}_{17} \mathrm{~N}_{3}$ (373.16): calculated. C 83.62, H 5.13, N 11.25; found C 83.43, H 5.01, N 11.22. $\mathrm{m} / z$ calculated for $\mathrm{C}_{26} \mathrm{H}_{19} \mathrm{~N}_{3}(\mathrm{M}+\mathrm{H})$ : 373.16, found: 373.3 .

(Z)-3-(4-(Diphenylamino)phenyl)-2-(pyridine-4-yl)acrylonitrile (5). Yield: $72 \%$. M.p.: $108-112{ }^{\circ} \mathrm{C}$ IR $\left(\mathrm{KBr}, \mathrm{cm}^{-1}\right): 3433(\mathrm{~N}-\mathrm{H})$, $2924(\mathrm{C}-\mathrm{H}), 2208(\mathrm{C} \equiv \mathrm{N}), 1579$ (aromatic $\mathrm{C}=\mathrm{C}), 1488(\mathrm{C}-\mathrm{H}$ double bond), $756(\mathrm{CH}) .{ }^{1} \mathrm{H}$ NMR $\left(300 \mathrm{MHz}, \mathrm{CDCl}_{3}\right) \delta 8.59$ 
(s, 1H), 8.06-8.04 (d, 1H), 7.82-7.80 (d, 1H), 7.52-7.49 (d, 2H), 7.48-7.46 (d, 1H), 7.35-7.33 (m, 1H), $7.32(\mathrm{~m}, 4 \mathrm{H}), 7.18-7.16(\mathrm{~m}$, $6 \mathrm{H}), 7.05-7.03(\mathrm{~d}, 2 \mathrm{H}) .{ }^{13} \mathrm{C} \mathrm{NMR}\left(75 \mathrm{MHz}, \mathrm{CDCl}_{3}\right) \delta$ 151.86, $150.57,149.49,146.45,144.53,137.27,131.55,129.61,125.94$, $124.62,122.77,120.85,120.41,118.70,105.92 . \quad \mathrm{C}_{26} \mathrm{H}_{17} \mathrm{~N}_{3}$ (373.16): calculated. C 83.62, H 5.13, N 11.25; found C 83.68, $\mathrm{H}$ 5.22, $\mathrm{N}$ 11.17. $\mathrm{m} / \mathrm{z}$ calculated for $\mathrm{C}_{26} \mathrm{H}_{19} \mathrm{~N}_{3}(\mathrm{M}+\mathrm{H})$ : 373.16, found: 373.2 .

(Z)-3-(4-(Diphenylamino)phenyl)-2-(pyridine-4-yl)acrylonitrile (6). Yield: $89 \%$. M.p.: $153-156{ }^{\circ} \mathrm{C}$ IR $\left(\mathrm{KBr}, \mathrm{cm}^{-1}\right)$ : $3432(\mathrm{~N}-\mathrm{H}), 3039$ $(\mathrm{C}-\mathrm{H}), 2207(\mathrm{C} \equiv \mathrm{N}), 1578$ (aromatic $\mathrm{C}=\mathrm{C}), 1487(\mathrm{C}-\mathrm{H}$ double bond), $698(\mathrm{CH}) .{ }^{1} \mathrm{H}$ NMR $\left(300 \mathrm{MHz}, \mathrm{CDCl}_{3}\right) \delta 8.64(\mathrm{~s}, 2 \mathrm{H}), 7.83-$ $7.81(\mathrm{~d}, 2 \mathrm{H}), 7.59-7.52(\mathrm{~s}, 1 \mathrm{H}), 7.36-7.32(\mathrm{~d}, 2 \mathrm{H}), 7.29-7.27(\mathrm{~m}, 4 \mathrm{H})$, 7.18-7.14 (m, 6H), 7.12-7.03 (d, 2H). ${ }^{13} \mathrm{C}$ NMR (75 MHz, $\mathrm{CDCl}_{3}$ ) $\delta$ 151.02, 150.46, 146.20, 144.34, 142.54, 131.49, 129.71, 129.66, 126.09, 125.07, 124.94, 120.11, 119.60, 117.84, 104.38. $\mathrm{C}_{26} \mathrm{H}_{17} \mathrm{~N}_{3}$ (373.16): calculated. C 83.62, H 5.13, N 11.25; found C 83.68, H 5.24, $\mathrm{N}$ 11.12. $\mathrm{m} / \mathrm{z}$ calculated for $\mathrm{C}_{26} \mathrm{H}_{19} \mathrm{~N}_{3}(\mathrm{M}+\mathrm{H})$ : 373.16 , found: 373.2 .

\section{Characterization}

NMR spectra were measured on a Bruker $300 \mathrm{MHz}$ AVANCE-II. The fluorescence spectra and absolute quantum yields for all compounds in the solid state were recorded using a Jasco fluorescence spectrometer-FP-8300 instrument equipped with an integrating sphere and a calibrated light source. The Fourier transform infrared (FT-IR) spectra were recorded on a JASCO FT-IR spectrometer model 400 plus using $\mathrm{KBr}$ pellets. Mass spectra were recorded using a Bruker 320-MS triple quadrupole mass spectrometer using the direct probe insertion method. Powder X-ray diffraction (PXRD) patterns were measured using an XRDBruker D8 Advance XRD with $\mathrm{Cu} \mathrm{K} \alpha$ radiation $(\lambda=1.54050 \AA)$ at room temperature. Single crystals were coated with paratone-N oil and the diffraction data were measured with synchrotron radiation $(\lambda=0.62998 \AA)$ on a ADSC Quantum-210 detector at 2D SMC with a silicon (111) double crystal monochromator (DCM) at the Pohang Accelerator Laboratory, Korea. CCDC No. 2027366-2027372. $\dagger$

\section{Results and discussion}

Isomeric fluorophores (1-6, Scheme 1a) were synthesized by condensing carbazole benzaldehyde/triphenylamine aldehyde with pyridine acetonitrile isomers (Scheme S1, ESI $\dagger$ ). Structurally 1-6 differed only slightly. 1-3 contain planar carbazole whereas twisted propeller triphenylamine is found in 4-6. Nitrogen positions in 1-3 and 4-6 varied from ortho to para. Absorption of 1-3 and 4-6 did not show significant change with solvent polarity (Fig. S1 and S2, ESI $\dagger$ ). 1-3 showed intramolecular charge transfer (ICT) absorption peaks between 370 and $380 \mathrm{~nm}$ in different solvents whereas 4-6 showed ICT between 405 and $420 \mathrm{~nm}$. On the other hand, fluorescence spectra showed a large shift of $\lambda_{\max }$ across solvent polarities (Fig. S3 and S4, ESI $\dagger$ ). 1-6 showed red shifted weak fluorescence in polar solvents but a comparatively strong blue shifted fluorescence was observed in non-polar solvents (Fig. S3, S4 and Table S1, ESI $\dagger$ ). This strongly suggests the involvement of a twisted intramolecular charge
Table 1 Fluorescence efficiency of $\mathbf{1 - 6}$ in the solid state

\begin{tabular}{lllll}
\hline & & \multicolumn{2}{c}{ Absolute quantum yield $\left(\Phi_{\mathrm{f}}\right) \%$} \\
\cline { 3 - 5 } Compounds & $\lambda_{\max }(\mathrm{nm})$ & Crystal & Crushed & Heated \\
\hline 1-G & 536 & 13.4 & 7.4 & 10.4 \\
1-O & 581 & 20.2 & 12.7 & 18.4 \\
$\mathbf{2}$ & 516 & 23.5 & 18.9 & 20.9 \\
3-G & 537 & 25.3 & 15.0 & 21.9 \\
3-Y & 554 & 18.1 & 8.0 & 14.7 \\
3-O & 567 & 13.3 & 4.9 & 10.9 \\
$\mathbf{4}$ & 604 & 12.2 & 14.6 & 14.6 \\
$\mathbf{5}$ & 561 & 11.3 & 8.5 & 10.4 \\
$\mathbf{6}$ & 565 & 15.3 & 11.0 & 14.6 \\
\end{tabular}

transfer state (TICT). ${ }^{52}$ In contrast, 1-6 showed strongly enhanced fluorescence in the solid state (Table 1). Unlike in solution, carbazole based 1-3 exhibited a stronger fluorescence compared to 4-6. Aggregation studies of 1-6 further confirmed the solid state luminescence enhancement (Fig. 1 and Fig. S5-S8, $\mathrm{ESI} \dagger$ ). For example, 3 in $\mathrm{CH}_{3} \mathrm{CN}$ showed a weak fluorescence at $563 \mathrm{~nm}$. Increasing water fraction showed a decrease of fluorescence intensity with a slight red shift in the $\lambda_{\max }(575 \mathrm{~nm})$ due to the increase in local polarity. The fluorescence was completely quenched at $70 \%$ water fraction.

However, further increase of the water fraction (above 80\%) showed a strong increase of fluorescence intensity due to the aggregation of molecules with increasing water fraction. The fluorescence $\left(\lambda_{\max }\right)$ was blue shifted with increasing water fraction (545 $\mathrm{nm}$ at $80 \%$ and $539 \mathrm{~nm}$ at 100\%). Digital images also confirmed the conversion of weak yellow fluorescence to strong green with increasing water ratio in $\mathrm{CH}_{3} \mathrm{CN}$ (Fig. 1a). Other isomers (1, 2 and 4, 5) also exhibited a similar increase of fluorescence intensity with increasing water fraction (Fig. S5S8, ESI $\dagger$ ). Surprisingly, 6 exhibited drastically different fluorescent aggregate formation with increasing water fraction. 6 showed a red shifted fluorescence from $575 \mathrm{~nm}$ to $610 \mathrm{~nm}$ at $80 \%$ water fraction (Fig. 1c). Further increase of water fraction (90 and 100\%) showed blue shifted fluorescence (575 to $567 \mathrm{~nm}$ ). Thus water percentage clearly influenced the molecular self-assembly of $\mathbf{6}$ which was different from other isomers.

Molecular self-assembly of 1-6 varied with increasing water fraction and time that led to tunable fluorescence. After $48 \mathrm{~h}$, 1 showed yellow fluorescence particles at 70 and $80 \%$ water fraction (Fig. S5c, ESI $\dagger$ ). The peak intensity at $488 \mathrm{~nm}$ becomes stronger and both peaks appeared with almost equal intensity. In contrast, 2 did not show any significant change after 48 h (Fig. S6c, ESI $\dagger$ ). But 3 exhibited green (70\%), yellow (80\%) and greenish-yellow (90 and $100 \%$ ) fluorescent particles at different water fractions after $48 \mathrm{~h}$ (Fig. 2). On the other hand, 4 and $\mathbf{5}$ did not show a significant change of fluorescence with time (Fig. S7 and S8, ESI $\dagger$ ). After $48 \mathrm{~h}$, the fluorescence of 6 was red shifted for 90 and 100\% water fraction and matched with the fluorescence of $80 \%$ water fraction (Fig. S9, ESI $\dagger$ ). Except 6, the fluorescence of all other molecules blue shifted with time. Thus the molecular structure and water fraction influenced molecular aggregation and fluorescence tuning. ${ }^{53,54}$

In order to explore the morphological evolution at different water fractions, fluorescence microscopy and scanning electron 

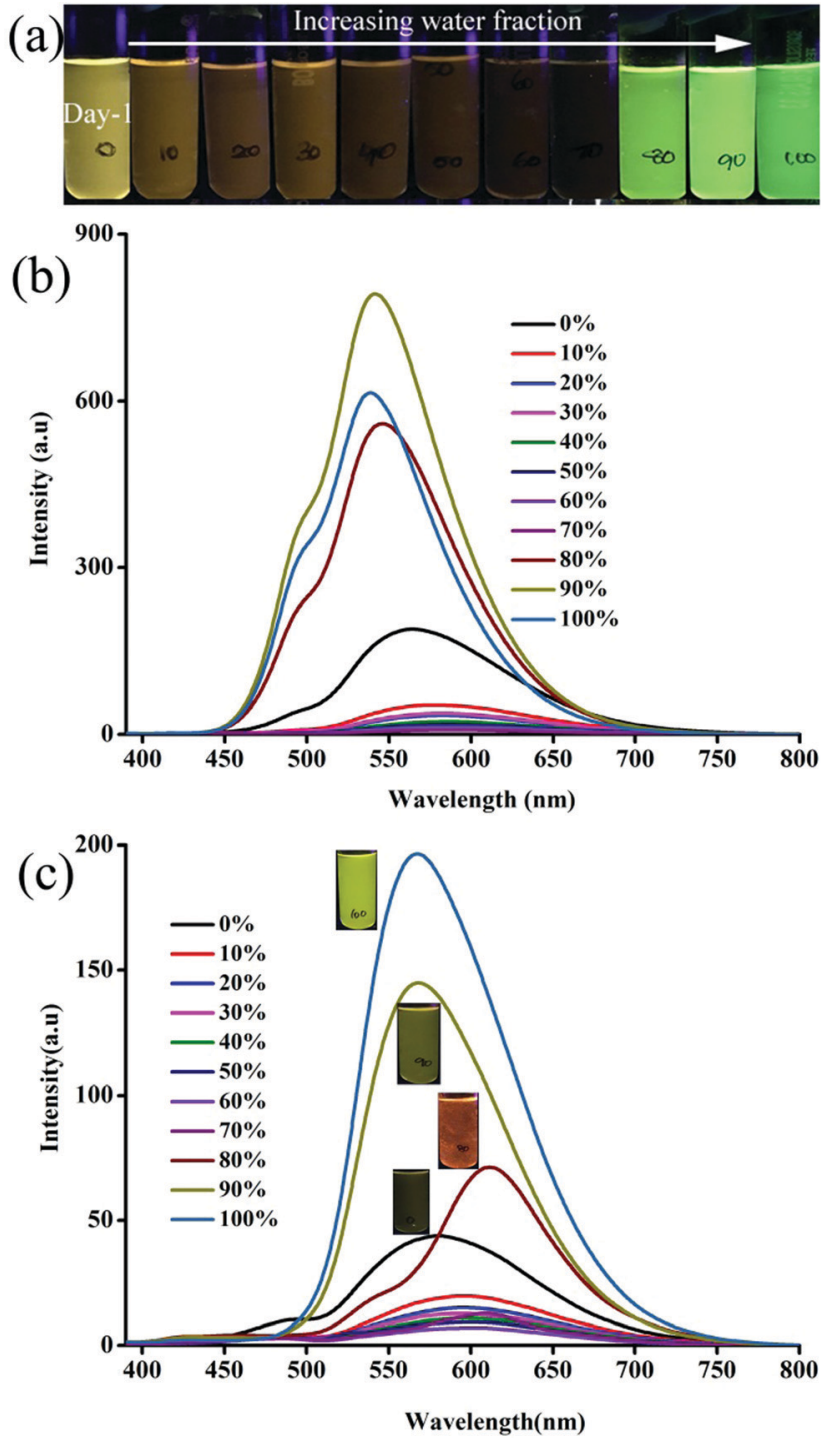

Fig. 1 Digital images and fluorescence spectra (a and b) 3 and (c) 6 with increasing water fraction in $\mathrm{CH}_{3} \mathrm{CN}$ : water mixture. $\lambda_{\text {exc }}=365 \mathrm{~nm}$ (for the digital images) and $370 \mathrm{~nm}$ (for the spectra).

microscopy (SEM) analyses were performed. Fluorescence microscopy studies of 1 revealed 1D nanostructures with red, green and yellow fluorescent particles at 60, 70 and $90-100 \%$ water fraction, respectively (Fig. S10 and S11, ESI $\dagger$ ). However, SEM showed featureless particles along with a few flat 1D nanoparticles at $60 \%$ and only featureless particles at $100 \%$ water fraction (Fig. S11, ESI $\dagger$ ). Although 2 did not show any fluorescence modulation, it showed a clear morphological change with increasing water fraction. Green fluorescent 1D nanostructures were observed at 80 and $90 \%$ water fraction whereas small particles were formed at $100 \%$ water fraction (Fig. S12, ESI $\dagger$ ). SEM also confirmed the formation of neat 1D nanostructures at $80 \%$ water fraction (Fig. S13, ESI $\dagger$ ). Along with a 1D nanostructure, small particles also formed at $90 \%$ and only single nanoparticles were found at 100\% water (Fig. S14 and S15, ESI $\dagger$ ). 3 showed rectangle shaped crystalline particles with green

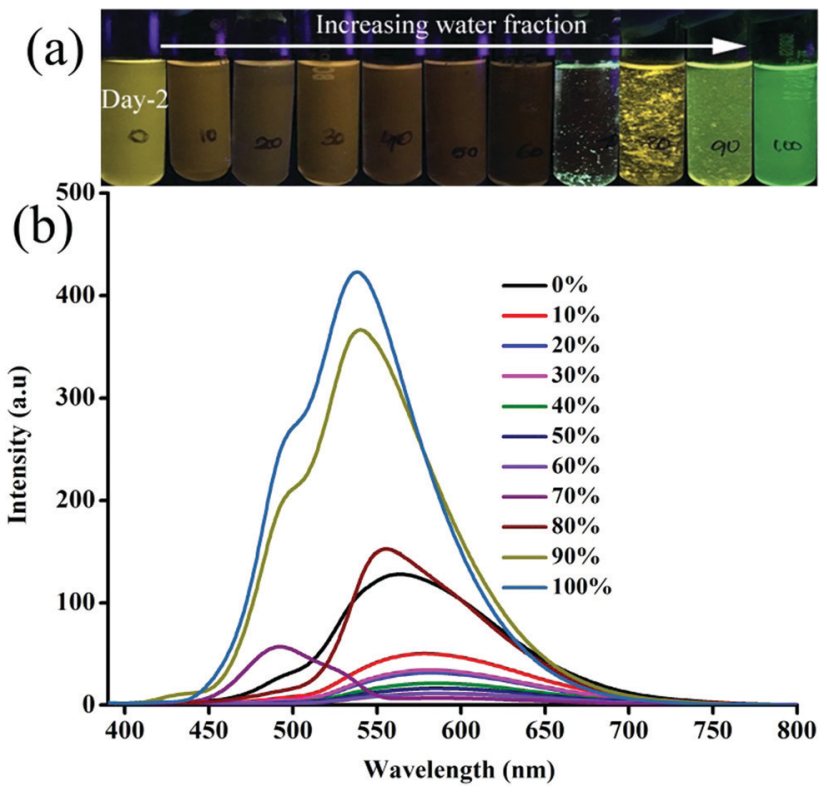

Fig. 2 (a) Digital images and (b) fluorescence spectra of 3 at different water fraction in $\mathrm{CH}_{3} \mathrm{CN}$ : water in day 2. $\lambda_{\text {exc }}=365 \mathrm{~nm}$ (for the digital images) and $370 \mathrm{~nm}$ (for the spectra).

fluorescence at 70\% water fraction (Fig. 3a). Orange fluorescent 1D nanostructures along with green fluorescent nanoparticles were formed at $80 \%$ and $90 \%$ water fraction, respectively (Fig. $3 \mathrm{~b}$ and c). But green fluorescent thin needle/flakes were formed at $100 \%$ water (Fig. 3d). SEM also showed the formation of crystals, 1D nanostructures, 1D nanostructures along with nanoparticles and only nanoparticles with increasing water fraction from 70 to 100\% (Fig. 4 and Fig. S16-S18, ESI $\dagger$ ). 4 and 5 showed only green fluorescent nanostructures from 70 to $100 \%$ water fraction (Fig. S19 and S20, ESI $\dagger$ ). However, SEM of 4 showed 1D nanostructures at $70 \%$ water fraction and nanoparticles at $100 \%$ water fraction (Fig. S21 and S22, ESI †). 5 exhibited spherical nanoparticles along with $1 \mathrm{D}$ nanostructures at $100 \%$ water fraction (Fig. S23, ESI $\dagger$ ). But 6 showed only single nanoparticle formation from 80 to $100 \%$ water fraction (Fig. S24 and S25, ESI $\dagger$ ). It showed red fluorescent nanoparticles at $80 \%$ and green fluorescent nanoparticles at 90 and $100 \%$ water fraction. The comparison of SEM images revealed that carbazole based 2 and $\mathbf{3}$ produced clear sharp edged ID nanostructures compared to triphenylamine based $\mathbf{4}$ and $\mathbf{5}$.

The observation of different self-assemblies and fluorescence modulations suggested the possibility of realizing polymorphic structures with tunable fluorescence. Hence various solvents have been explored for growing crystals of 1-6. Interestingly, 1 produced green (1-G) and orange (1-O) fluorescent crystals by slow evaporation from $\mathrm{CHCl}_{3}$ and $\mathrm{CHCl}_{3}-\mathrm{CH}_{3} \mathrm{OH}(1: 1)$, respectively. But 2 produced only green fluorescent crystals (Fig. 5a). 3 produced green (3-G), yellow (3-Y), orange (3-O) and red (3-R) fluorescent crystals from $\mathrm{CHCl}_{3}: \mathrm{CH}_{3} \mathrm{OH}(1: 1), \mathrm{CHCl}_{3}$ : hexane $(1: 1), \mathrm{CHCl}_{3}$ : $\mathrm{CH}_{3} \mathrm{OH}(3: 1)$ and $\mathrm{CHCl}_{3}$ : hexane (diffusion), respectively (Fig. 5a). This resulted in tunable solid state fluorescence between 516 and 645 nm (Fig. 5a). In contrast, 4-6 did not produce any fluorescent polymorphs and exhibited only isomerism dependent fluorescence 


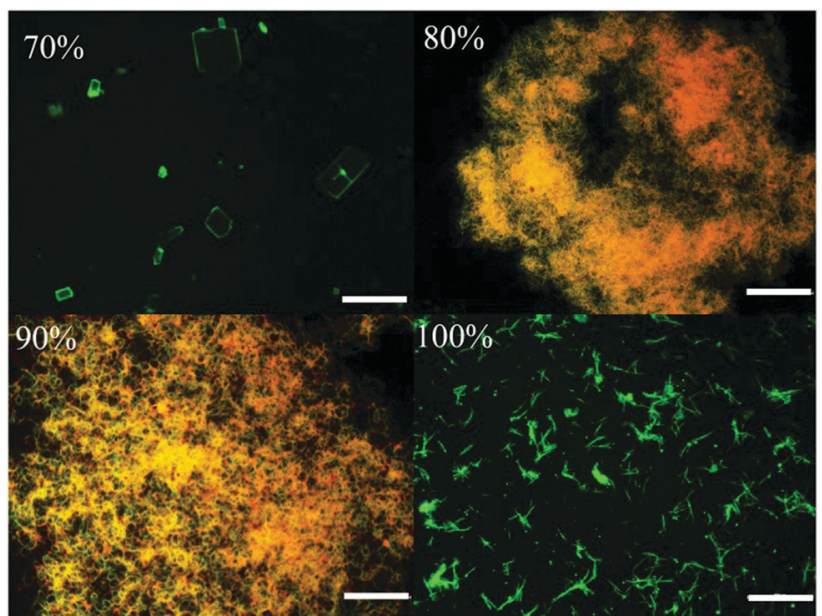

Fig. 3 Fluorescent microscopic images of $\mathbf{3}$ at different water fractions in a $\mathrm{CH}_{3} \mathrm{CN}$-water mixture (scale bar $=500 \mu \mathrm{m}$ ).

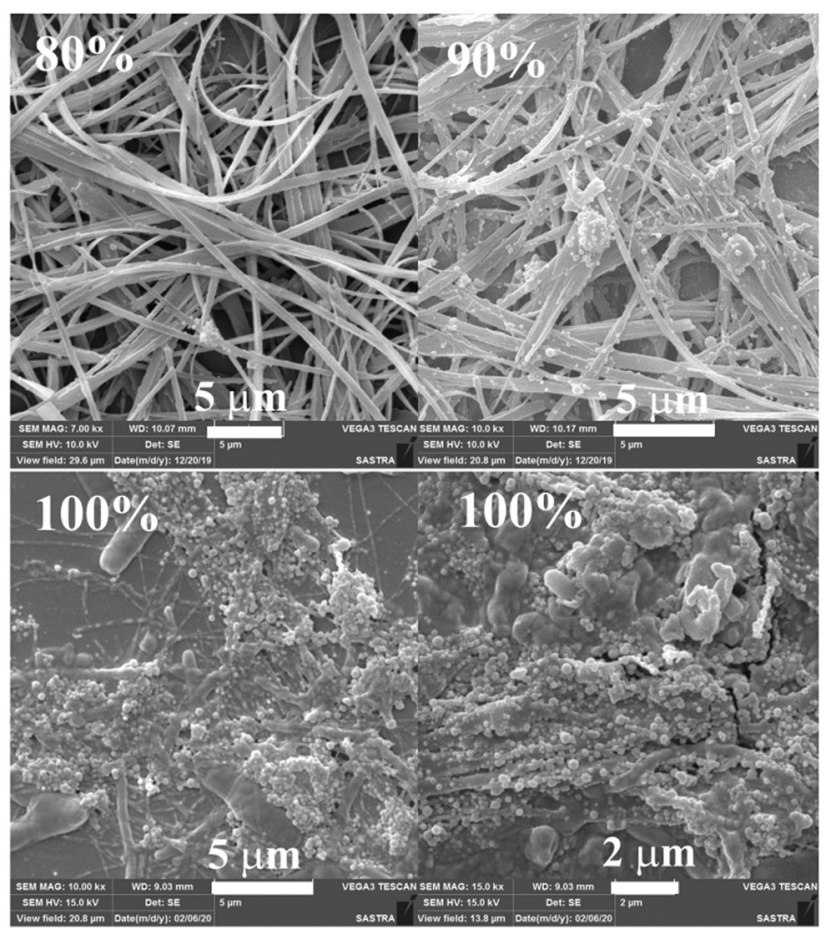

Fig. 4 SEM images of 3 at different water fractions in a $\mathrm{CH}_{3} \mathrm{CN}$-water mixture (scale bar $=1 \mu \mathrm{m}$ ).

tuning (Fig. 5b). 4 showed solid state fluorescence at $603 \mathrm{~nm}$ whereas 5 and 6 showed fluorescence at 561 and $566 \mathrm{~nm}$, respectively (Fig. 5b). The appearance of double fluorescence peaks in 1-G, 3-G and 3-Y might be attributed to the lack of electronic communication between donor (carbazole) and acceptor units (cyanostilbene) and exhibiting fluorescence from carbazole and cyanostilbene units separately. Single crystal structural analysis has been performed to gain insight into fluorescence tuning (Tables S3-S9, ESI $\dagger$ ). Structural analysis showed that the molecules adopted a twisted conformation in the crystal lattice (Fig. 6 and
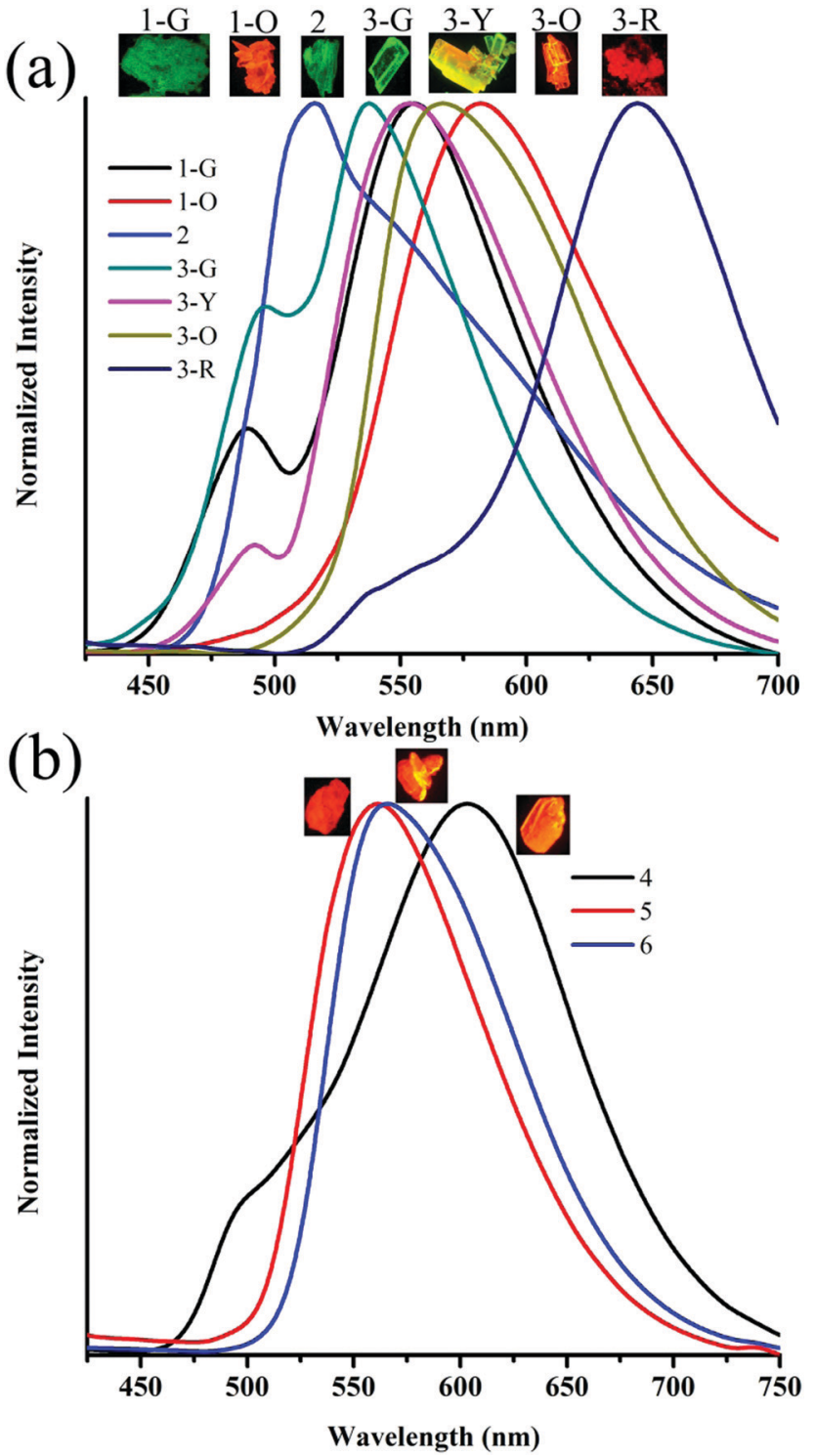

Fig. 5 Solid state fluorescence spectra of (a) 1-3 and (b) 4-6. Inset shows the digital fluorescence images of crystals. $\lambda_{\mathrm{exc}}=365 \mathrm{~nm}$ (for digital images) and $370 \mathrm{~nm}$ (for spectra).

Table S2, ESI $\dagger$ ). 1-G and 1-O showed similar conformation with only a slight conformational twist difference in the crystal lattice (Table S2 and Fig. S26, ESI $\dagger$ ). Molecules displayed similar packing and intermolecular interactions. Simulated PXRD of 1-G and 1-O also perfectly matched each other (Fig. S27, ESI $\dagger$ ). 1-G showed dimer formation with opposite molecular arrangement via weak intermolecular interactions between cyano nitrogen and phenyl hydrogen (Fig. 7). 2 showed multiple intermolecular interactions; dimer formation with opposite molecular arrangement via hydrogen bonding between cyano nitrogen and phenyl/pyridine hydrogen and $\mathrm{C}-\mathrm{H} \cdots \pi$ interactions between carbazole and pyridine hydrogen (Fig. 7 and Fig. S28, ESI $\dagger$ ). Only crystals of green and yellow forms of 3 were of good quality to solve the structure. Similar to 1, 3-G and 3-Y also differed only slightly in the conformational twist and displayed similar intermolecular interactions and 

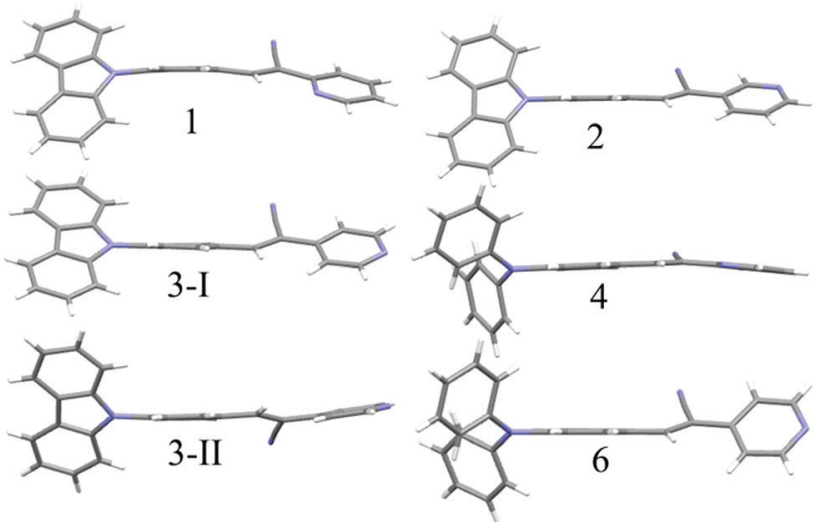

Fig. 6 Molecular conformation of different isomers in the crystal lattice. $\mathrm{C}$ (grey), $\mathrm{N}$ (blue) and $\mathrm{H}$ (white).

packing (Fig. S29, S30 and Tables S2, S6, S7, ESI $\dagger$ ). The intermolecular interaction between cyano nitrogen and phenyl hydrogen produced dimers with opposite molecular arrangements (Fig. 7). The asymmetric unit of 3-G/3-Y contained two molecules with different conformations (Fig. S31, ESI $\dagger$ ). Simulated and experimental PXRD of 3-G and 3-Y also matched perfectly (Fig. S32 and S33, ESI $\dagger$ ). However, 3-O and 3-R showed different PXRD patterns and confirmed the polymorphism (Fig. S33, ESI $\dagger$ ). Thus the fluorescence tuning of 1-G and 1-O, and 3-G and $\mathbf{3 - Y}$ is attributed to crystal habits or morphology differences. ${ }^{55}$ But $\mathbf{3 - O}$ and $\mathbf{3 - R}$ are fluorescent polymorphs. 4 showed a parallel arrangement of molecules in the crystal lattice via $\pi \cdots \pi$ interactions between pyridine and phenyl group (Fig. 7 and Fig. S34, ESI†). 6 showed dimer

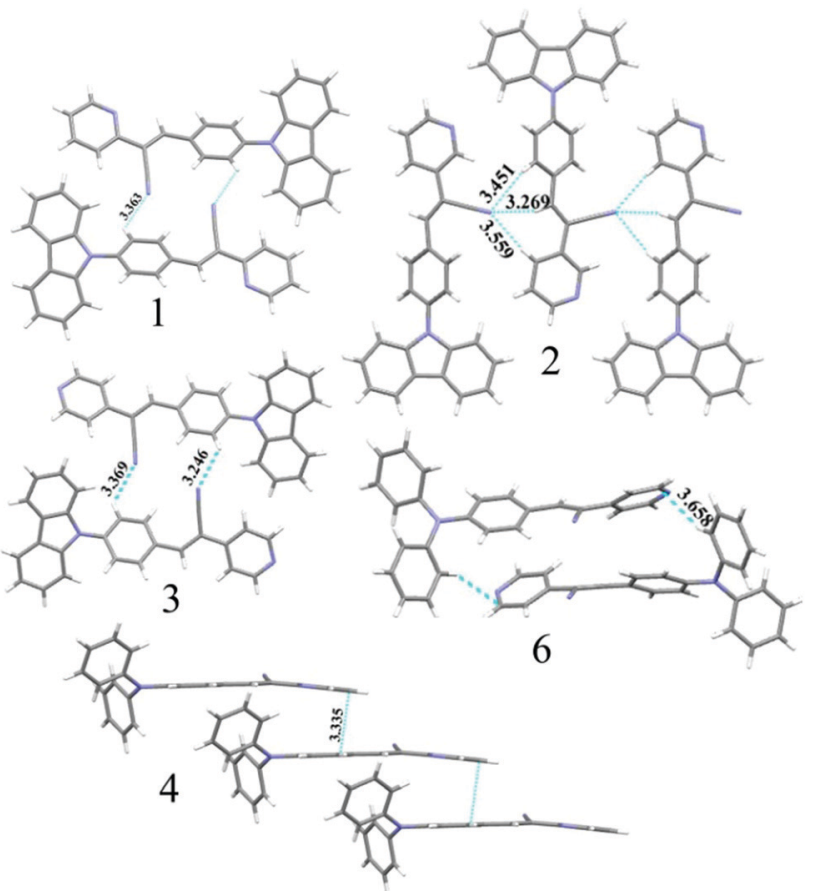

Fig. 7 Molecular interactions in the crystal lattice of 1-4 and 6. C (grey), $\mathrm{N}$ (blue) and $\mathrm{H}$ (white). Dotted lines indicate the hydrogen bonding, $\mathrm{C}-\mathrm{H} \cdots \pi$ and $\pi \cdots \pi$ interactions in $\AA$. formation with opposite molecular arrangement via weak $\mathrm{C}-\mathrm{H} \cdots \pi$ interactions (Fig. 7). The crystal quality of 5 was very poor and the structure could not be solved. The fluorescence of 4 is strongly red shifted compared to $\mathbf{5}$ and $\mathbf{6}$ due to the formation of a parallel arrangement of molecules. Solid state structural studies indicate that $\mathbf{1}, \mathbf{3}$ and $\mathbf{6}$ showed relatively weak intermolecular interactions compared to 2 and 4 . Aggregation studies of $\mathbf{1}, 3$ and 6 showed tunable fluorescence via different selfassemblies. 3 also produced fluorescent polymorphs. The stronger intermolecular interactions in $\mathbf{2}$ and $\mathbf{4}$ might drive the molecules to adopt a more preferred arrangement whereas weaker interactions provided the opportunity to form different structural assemblies in 1, 3 and 6. Hence, the delicate balance of solvent mixtures and intermolecular interactions leads to a tunable fluorescence.

The strong solid state fluorescence with a twisted molecular conformation of 1-6 prompted the exploration of mechanofluorochromism (MFC). Interestingly, carbazole based 1-3 showed clear MFC whereas triphenylamine based $\mathbf{4}$ and $\mathbf{5}$ did not show fluorescence modulation (Fig. 8a and Fig. S35-S37, ESI $\dagger$ ). But 6 showed fluorescence switching upon crushing and heating (Fig. S38, ESI $\dagger$ ). Crystals of 1-G showed two fluorescence peaks at 488 and $540 \mathrm{~nm}$. Crushing showed a significant reduction of fluorescence intensity whereas heating increased the fluorescence intensity of longer wavelength peaks with slight red shifting to $555 \mathrm{~nm}$ (Fig. S35a, ESI $\dagger$ ). The crystals of 1-O showed fluorescence at $580 \mathrm{~nm}$ and blue shifted to $560 \mathrm{~nm}$ by slight breaking (Fig. S35b, ESI $\dagger$ ). ${ }^{56}$ Mechanical crushing further blue shifted the fluorescence to $505 \mathrm{~nm}$ and heating red shifted it to $558 \mathrm{~nm}$. The blue shifting of 1-O fluorescence upon slight breaking might be attributed to the disruption of long range intermolecular interactions and crystal morphology changes. ${ }^{54,55,57}$ MFC studies of 2 showed fluorescence switching between 504 and $474 \mathrm{~nm}$ upon crushing and heating (Fig. S35c, ESI $\dagger$ ). 3-G showed two fluorescence peaks at 490 and $535 \mathrm{~nm}$ (Fig. 5). The fluorescence at $490 \mathrm{~nm}$ was reduced by crushing whereas the peak at 535 was completely shifted toward $490 \mathrm{~nm}$ upon heating (Fig. 8a). Crushing of 3-Y showed a blue shifting of the fluorescence from 560 to $546 \mathrm{~nm}$ and heating produced an additional small hump at $488 \mathrm{~nm}$ (Fig. S36a, ESI $\dagger$ ). Slight breaking of 3-O crystals showed blue shifting of the fluorescence from 580 to $561 \mathrm{~nm}$ (Fig. S36b, ESI $\dagger$ ). The fluorescence was significantly reduced upon crushing and showed two fluorescence peaks at 486 and $550 \mathrm{~nm}$ while heating caused an effect that matched with that on the fluorescence of 3-G after heating. Crushing of 3-R produced a fluorescence similar to 3-G crushed solids and showed an MFC also similar to 3-G (Fig. S36c, ESI $\dagger$ ). Heating crystals of 3-O and 3-R also showed blue shifted fluorescence that matched with 3-G (Fig. S39, ESI $\dagger$ ). Thus any external disturbances (mechanical or heating) of 3-Y, 3-O and 3-R caused a conversion to 3-G which suggests that the 3-G form might be more stable compared to 3-Y, 3-O and 3-R. Crystals of 6 showed blue shifted fluorescence (565 to $554 \mathrm{~nm}$ ) by slight breaking/crushing and heating exhibited further blue shifting of the fluorescence to $538 \mathrm{~nm}$ (Fig. S38, ESI $\dagger$ ). The comparison of molecular conformation in the crystal lattice of 1-6 suggests that the acceptor pyridine unit displayed a twisted conformation in 1-3 and 6 (Fig. 6). The pyridine and phenyl groups showed a coplanar 


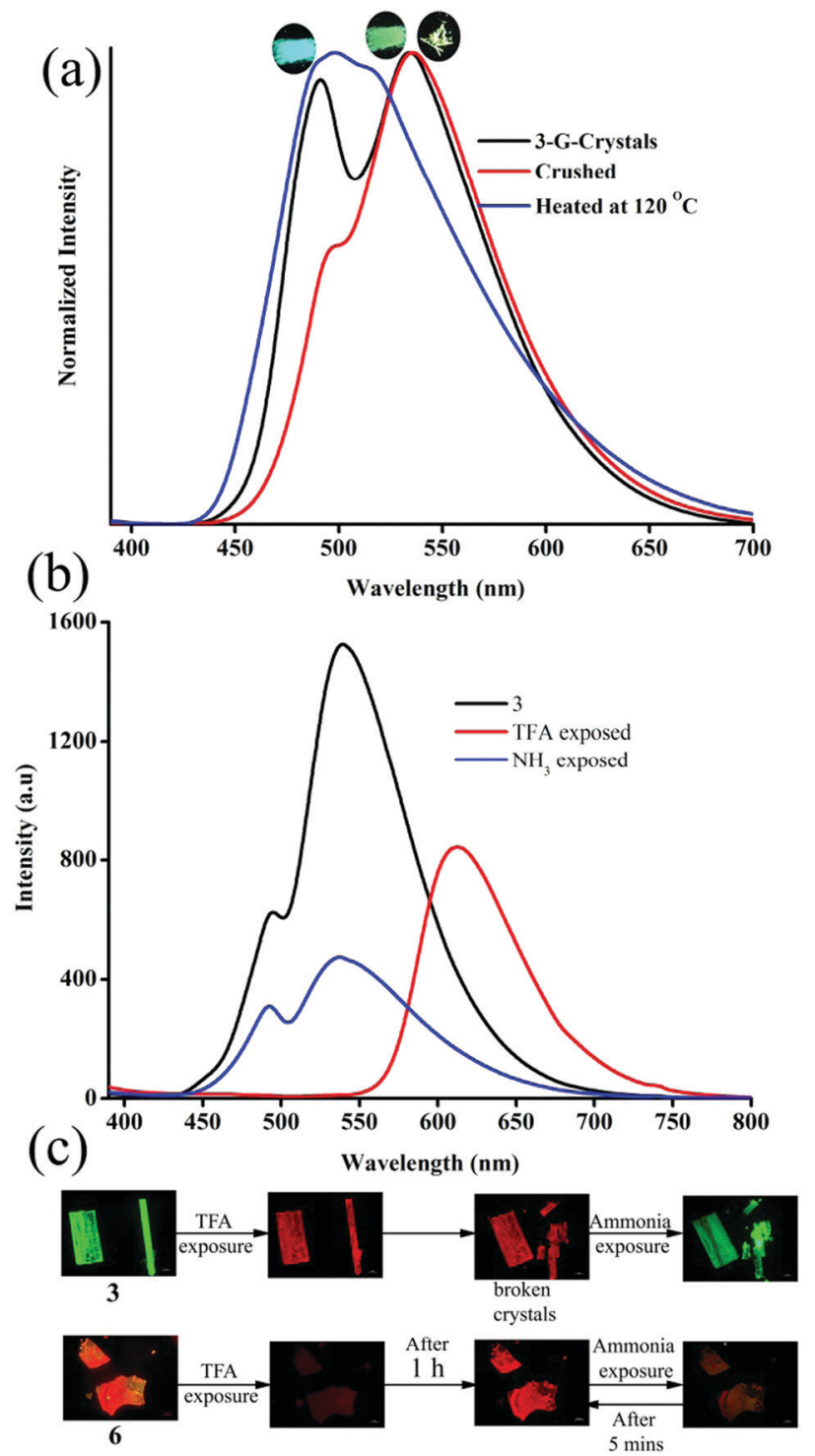

Fig. 8 (a) Mechanofluorochromism and (b) halochromism of 3-G. (a) Digital images of halochromic fluorescence switching of 3 and $6 . \lambda_{\text {exc }}=365 \mathrm{~nm}$ (for digital images) and $370 \mathrm{~nm}$ (for spectra).

conformation in 4 . In general, the twisted molecular conformation adopts a more planar structure upon applying mechanical pressure and partial/complete amorphous phase formation that leads to fluorescence tuning. ${ }^{12-19}$ The coplanar conformation and parallel arrangement might not undergo further conformational change upon crushing and hence might not be showing fluorescence switching. Further comparison of MFC revealed an unusual blue shifting of fluorescence by crushing of $\mathbf{1}$ and heating induced red shifting of fluorescence. All other five compounds (2-6) showed red shifting of fluorescence by crushing and blue shifting by heating. The planarization of molecules or amorphous phase formation by mechanical crushing often induced red shifted weak fluorescence due to the formation of low energy species and a nonradiative 'dark' state. ${ }^{58-61}$ Only a few limited molecules showed pressure induced blue shifted fluorescence. ${ }^{62,63}$ However, the reason for the blue shifting of 1 is not clear at present. It is noted that $\mathbf{1}$ and $\mathbf{3}$ showed similar dimer formation but $\mathbf{3}$ exhibited red shifted fluorescence upon crushing. PXRD studies of 1-3 indicate that the crystalline phase was converted to amorphous/partial amorphous upon crushing and regenerated to crystalline by heating. Hence the reversible phase transformation might be responsible for fluorescence switching (Fig. S40, ESI $\dagger$ ).

The presence of acid responsive pyridine unit was utilized for halochromic fluorescence switching. Exposure of trifluoroacetic acid (TFA) on powdered 3-G showed strongly red shifted fluorescence (610-615 nm) and $\mathrm{NH}_{3}$ exposure reversed to the initial state (Fig. 8b and Fig. S41, S42, ESI $\dagger$ ). Similarly 2, 4 and 6 also showed reversible halochromic fluorescence switching upon TFA/ $\mathrm{NH}_{3}$ exposure (Fig. S43-S45, ESI $\dagger$ ). 5 exhibited offon fluorescence switching by TFA and $\mathrm{NH}_{3}$ exposure (Fig. S46, $\mathrm{ESI} \dagger$ ). The reversible halochromic fluorescence switching could be demonstrated for several cycles without significant change of fluorescence (Fig. S47, ESI $\dagger$ ). It was observed that 1 and 3 fluorescence self-reversed to the initial state with TFA exposure without $\mathrm{NH}_{3}$ exposure after $1 \mathrm{~h}$ (Fig. S48, ESI $\dagger$ ). But selfreversible fluorescence switching of 2 was relatively very slow compared to $\mathbf{1}$ and $\mathbf{3}$. In contrast, the very weak red shifted fluorescence of $\mathbf{6}$ after TFA exposure became strong without altering $\lambda_{\max }$ within $1 \mathrm{~h}$ (Fig. S49, ESI $\dagger$ ). Single crystals of 3-G and 6 also showed clean conversion of fluorescence from green/ yellow to red upon TFA exposure (Fig. 8c). $\mathrm{NH}_{3}$ exposure showed a complete reversal of fluorescence. The broken single crystals of 3 with TFA exposure also confirmed transformation of green to red fluorescence. Crystals of 6 TFA exposure initially showed very weak fluorescence but showed strongly enhanced fluorescence after $1 \mathrm{~h}$. 6 self-reversed to red fluorescence in 5 min with ammonia exposure. Thus carbazole based 1-3 showed self-reversed fluorescence switching to the initial state after TFA exposure whereas triphenylamine based 4-6 exhibited more stable red fluorescence with TFA exposure. Halochromic fluorescence switching of 1-6 has been utilized for fabricating rewritable fluorescence platforms. Since all the molecules showed halochromic fluorescence switching, 3 and 6 were chosen to demonstrate rewritable fluorescence platforms. The fluorophore-PMMA polymer composite was prepared by dissolving 3/6 $\left(10^{-3} \mathrm{M}\right)$ and PMMA (1 wt\%) in toluene. Filter paper coated with 3-PMMA showed a light green colour and writing with TFA showed a dark red colour (Fig. 9a). The written material can be erased immediately using $\mathrm{NH}_{3}$ or it can be self-erased in $30 \mathrm{~min}$. Instead of writing, TFA exposure converted the filter paper to red colour (Fig. S50, ESI $\dagger$ ). Further writing with $\mathrm{NH}_{3}$ showed blue fluorescence that slowly disappeared and red paper also slowly converted to blue. The process can be repeated by exposing to TFA again followed by writing. 3-PMMA on a glass plate showed blue fluorescence and converted to red fluorescence upon TFA exposure (Fig. 9b, c and Fig. S51, ESI $\dagger$ ). $\mathrm{NH}_{3}$ exposure converted it to blue fluorescence. It is noted that 3-PMMA on a glass plate also showed self-reversibility but took a longer time. Filter paper coated with 6-PMMA showed green fluorescence and TFA exposure converted it to red fluorescence (Fig. 10a). Writing with $\mathrm{NH}_{3}$ showed yellow fluorescence which can self erase or be erased using TFA. 
(a)
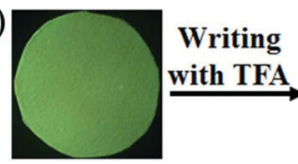

(b)

(c)
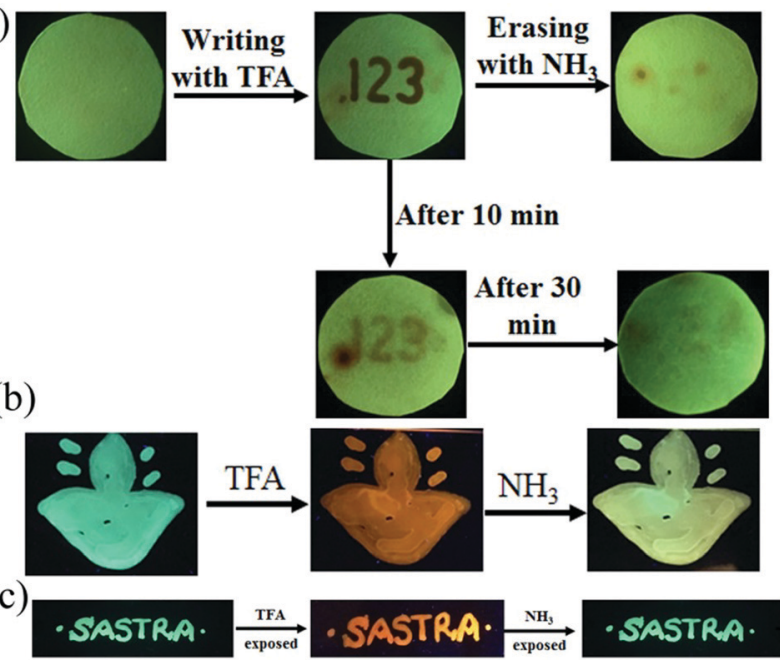

Erasing with NH $_{3}$ $\stackrel{\text { with } \mathrm{NH}_{3}}{\longrightarrow}$ After 10 min

Fig. 9 Fabricating rewritable/self-erasable fluorescent platforms using 3-PMMA on (a) a filter paper, (b) symbol on a glass plate and (c) word writing on a glass plate $\left(\lambda_{\text {exc }}=365 \mathrm{~nm}\right.$ ).

The writing can be repeated after self-erasing/TFA erasing. A symbol or letter written on a glass plate using 6-PMMA also exhibited halochromic fluorescence switching (Fig. 10b and Fig. $\mathrm{S} 52, \mathrm{ESI} \dagger)$. The material written on the glass plate showed green fluorescence and TFA exposure showed complete quenching of fluorescence. $\mathrm{NH}_{3}$ exposure regenerated the fluorescence but slowly turned to red. TFA exposed powders of 6 turned to bright red from the completely quenched state in $1 \mathrm{~h}$ but a word written on a glass plate using 6-PMMA took nearly 20 days (Fig. 10c and Fig. S53, ESI $\dagger$ ). 1-PMMA and 4-PMMA showed weak orange-red

(a)

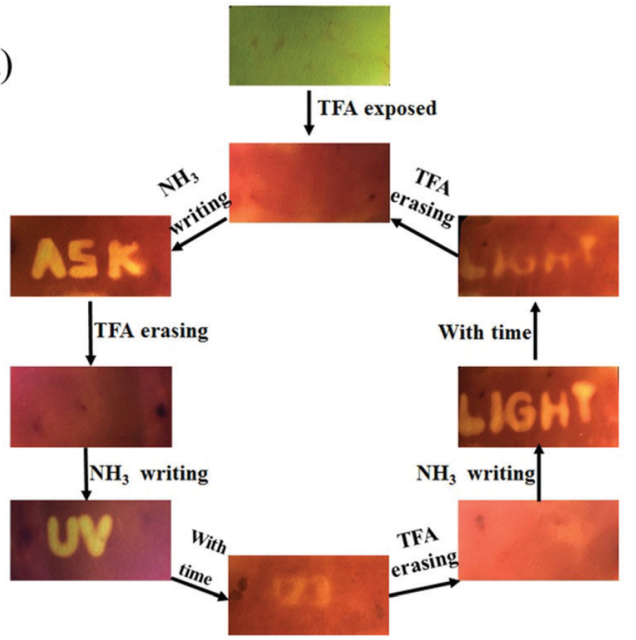

(b)

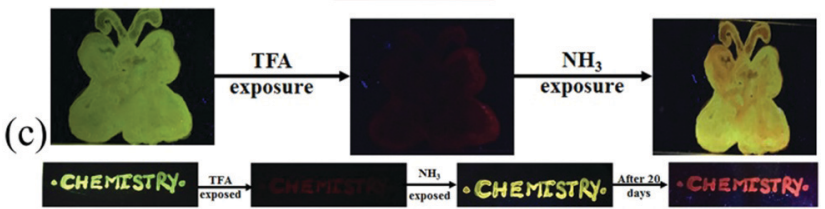

Fig. 10 Fabricating rewritable/self-erasable fluorescent platforms using 6-PMMA on (a) a filter paper, (b) a symbol on glass plate and (c) word writing on a glass plate $\left(\lambda_{\text {exc }}=365 \mathrm{~nm}\right.$ ). fluorescence and $\mathrm{NH}_{3}$ exposure reversed the fluorescence to the initial state (Fig. S54, ESI $\dagger$ ). 2-PMMA exhibited bright yellowgreen fluorescence after TFA exposure whereas 5-PMMA showed completely quenched fluorescence.

\section{Conclusions}

In summary, pyridine functionalized organic fluorescence molecules with partially planar carbazole and propeller triphenylamine donors (1-6) have been synthesized and demonstrated isomerism/structure controlled molecular self-assembly, tunable fluorescence (514 to $644 \mathrm{~nm}$ ) and stimuli-responsive fluorescence switching. The position of nitrogen and subtle structural changes strongly influenced the formation of fluorescent polymorphs and self-assembled nano/microstructures with tunable fluorescence. The evolution of intermolecular interactions with time led to the formation of 1D nanowires to nano/micro particles with varying water ratios. The varied molecular assembly showed tunable fluorescence from green to red. The relatively weak intermolecular interactions in the crystal lattice of 1,3 and 6 facilitated the formation of tunable fluorescent crystals/polymorphs with slight conformational differences and different molecular assemblies. Further MFC of 1-6 also showed isomer dependent reversible fluorescence switching. 1-3 and 6 exhibited crushing/heating induced reversible fluorescence whereas $\mathbf{4}$ and $\mathbf{5}$ did not show any MFC that could be attributed to the molecular packing in the crystal lattice. Acid responsive pyridine units have been exploited for demonstrating halochromic fluorescence switching by exposing acid/base and rewritable fluorescent platforms. 3 powder and 3-PMMA polymer thin films showed red shifted fluorescence that is self-reversed to the initial fluorescence state with time or upon $\mathrm{NH}_{3}$ exposure. In contrast, powders of 6 and 6-PMMA thin films produced more stable red shifted fluorescence states after TFA exposure. $\mathrm{NH}_{3}$ exposure switches the fluorescence to the initial state but it self-reverses to the TFA exposed fluorescence state with time. Contrasting halochromic fluorescence switching has been utilized for demonstrating selferasable and rewritable fluorescent platforms based on filter paper and glass plates.

\section{Conflicts of interest}

There are no conflicts to declare.

\section{Acknowledgements}

Financial support from the Science and Engineering Research Board (SERB), New Delhi, India (SERB No. EMR/2015/00-1891) is acknowledged with gratitude. The Deanship of scientific research at King Khalid University is greatly appreciated for funding (GRP-180-41). The CRF facility of SASTRA Deemed University is also acknowledged for absorption spectroscopy. X-ray crystallography at the PLS-II 2D-SMC beamline was supported in part by MSIP and POSTECH. 


\section{Notes and references}

1 A. J. C. Kuehne and M. C. Gather, Chem. Rev., 2016, 116, 12823-12864.

2 X. Cai and S. J. Su, Adv. Funct. Mater., 2018, 28, 1802558.

3 M. A. C. Stuart, W. T. S. Huck, J. Genzer, M. Müller, C. Ober, M. Stamm, G. B. Sukhorukov, I. Szleifer, V. V. Tsukruk, M. Urban, F. Winnik, S. Zauscher, I. Luzinov and S. Minko, Nat. Mater., 2010, 9, 101-113.

4 H. Zhou and J. W. Park, Org. Electron., 2015, 24, 272-279.

5 W. Lee, D. Kim, S. Lee, J. Park, S. Oh, G. Kim, J. Lim and J. Kim, Nano Today, 2018, 23, 97-123.

6 Y. Chen, W. Zhang, Z. Zhao, Y. Cai, J. Gong, R. T. K. Kwok, J. W. Y. Lam, H. H. Y. Sung, I. D. Williams and B. Z. Tang, Angew. Chem., Int. Ed., 2018, 57, 5011-5015.

7 Z. Chi, X. Zhang, B. Xu, X. Zhou, C. Ma, Y. Zhang, S. Liu and J. Xu, Chem. Soc. Rev., 2012, 41, 3878-3896.

8 X. Zhang, Z. Chi, Y. Zhang, S. Liu and J. Xu, J. Mater. Chem. C, 2013, 1, 3376.

9 Z. Yang, Z. Chi, Z. Mao, Y. Zhang, S. Liu, J. Zhao, M. P. Aldred and Z. Chi, Mater. Chem. Front., 2018, 2, 861-890.

10 C. Wang and Z. Li, Mater. Chem. Front., 2017, 1, 2174-2194.

11 S. P. Anthony, ChemPlusChem, 2012, 77, 518-531.

12 Y. Q. Dong, J. W. Y. Lam and B. Z. Tang, J. Phys. Chem. Lett., 2015, 6, 3429-3436.

13 S. J. Yoon, J. W. Chung, J. Gierschner, K. S. Kim, M. G. Choi, D. Kim and S. Y. Park, J. Am. Chem. Soc., 2010, 132, 13675-13683.

14 Y. Dong, J. Zhang, X. Tan, L. Wang, J. Chen, B. Li, L. Ye, B. Xu, B. Zou and W. Tian, J. Mater. Chem. C, 2013, 1, 7554.

15 P. S. Hariharan, G. Parthasarathy, A. Kundu, S. Karthikeyan, Y. Sagara, D. Moon and S. P. Anthony, Cryst. Growth Des., 2018, 18, 3971-3979.

16 M. Chen, L. Li, H. Nie, J. Tong, L. Yan, B. Xu, J. Z. Sun, W. Tian, Z. Zhao, A. Qin and B. Z. Tang, Chem. Sci., 2015, 6, 1932-1937.

17 Z. Ning, Z. Chen, Q. Zhang, Y. Yan, S. Qian, Y. Cao and H. Tian, Adv. Funct. Mater., 2007, 17, 3799-3807.

18 Y. Li, A. Shao, Y. Wang, J. Mei, D. Niu, J. Gu, P. Shi, W. Zhu, H. Tian and J. Shi, Adv. Mater., 2016, 28, 3187-3193.

19 P. Gayathri, M. Pannipara, A. G. Al-Sehemi and S. P. Anthony, New J. Chem., 2020, 44, 8680-8696.

20 J. Kunzelman, M. Kinami, B. R. Crenshaw, J. D. Protasiewicz and C. Weder, Adv. Mater., 2008, 20, 119-122.

21 H. Ito, M. Muromoto, S. Kurenuma, S. Ishizaka, N. Kitamura, H. Sato and T. Seki, Nat. Commun., 2013, 4, 2009.

22 G. Zhang, J. Lu, M. Sabat and C. L. Fraser, J. Am. Chem. Soc., 2010, 132, 2160-2162.

23 X. Luo, J. Li, C. Li, L. Heng, Y. Q. Dong, Z. Liu, Z. Bo and B. Z. Tang, Adv. Mater., 2011, 23, 3261-3265.

24 Z. Xie, C. Chen, S. Xu, J. Li, Y. Zhang, S. Liu, J. Xu and Z. Chi, Angew. Chem., Int. Ed., 2015, 54, 7181-7184.

25 M. Tanioka, S. Kamino, A. Muranaka, Y. Ooyama, H. Ota, Y. Shirasaki, J. Horigome, M. Ueda, M. Uchiyama, D. Sawada and S. Enomoto, J. Am. Chem. Soc., 2015, 137, 6436-6439.

26 W. Z. Yuan, Y. Tan, Y. Gong, P. Lu, J. W. Y. Lam, X. Y. Shen, C. Feng, H. H.-Y. Sung, Y. Lu, I. D. Williams, J. Z. Sun, Y. Zhang and B. Z. Tang, Adv. Mater., 2013, 25, 2837-2843.
27 Y. Zhang, Q. Song, K. Wang, W. Mao, F. Cao, J. Sun, L. Zhan, Y. Lv, Y. Ma, B. Zou and C. Zhang, J. Mater. Chem. C, 2015, 3, 3049-3054.

28 Q. Wang, S. Li, L. He, Y. Qian, X. Li, W. Sun, M. Liu, J. Li, Y. Li and G. Yang, ChemPhysChem, 2008, 9, 1146-1152.

29 Q. Qi, J. Qian, X. Tan, J. Zhang, L. Wang, B. Xu, B. Zou and W. Tian, Adv. Funct. Mater., 2015, 25, 4005-4010.

30 B. Huang, D. Jiang, Y. Feng, W. C. Chen, Y. Zhang, C. Cao, D. Shen, Y. Ji, C. Wang and C. S. Lee, J. Mater. Chem. C, 2019, 7, 9808-9812.

31 P. S. Hariharan, V. K. Prasad, S. Nandi, A. Anoop, D. Moon and S. P. Anthony, Cryst. Growth Des., 2017, 17, 146-155.

32 K. Wang, H. Xiao, L. Qian, M. Han, X. Wu, Z. Guo and H. Zhan, CrystEngComm, 2020, 22, 2166-2172.

33 H. Liu, Y. Shen, Y. Yan, C. Zhou, S. Zhang, B. Li, L. Ye and B. Yang, Adv. Funct. Mater., 2019, 29, 1901895.

34 H. Liu, Y. Gu, Y. Dai, K. Wang, S. Zhang, G. Chen, B. Zou and B. Yang, J. Am. Chem. Soc., 2020, 142, 1153-1158.

35 Y. Gu, K. Wang, Y. Dai, G. Xiao, Y. Ma, Y. Qiao and B. Zou, J. Phys. Chem. Lett., 2017, 8, 4191-4196.

36 Y. Gu, H. Liu, R. Qiu, Z. Liu, C. Wang, T. Katsura, H. Zhang, M. Wu, M. Yao, H. Zheng, K. Li, Y. Wang, K. Wang, B. Yang, Y. Ma and B. Zou, J. Phys. Chem. Lett., 2019, 10, 5557-5562.

37 P. S. Hariharan, C. Pan, S. Karthikeyan, D. Xie, A. Shinohara, C. Yang, L. Wang and S. P. Anthony, Dyes Pigm., 2020, 174, 108067.

38 H. W. Zheng, S. Li, M. Wu, Y. Kang, J. B. Li, Q. F. Liang, X. J. Zheng, D. C. Fang and L. P. Jin, J. Mater. Chem. C, 2020, 8, 4246-4252.

39 F. Liu, J. Tu, X. Wang, J. Wang, Y. Gong, M. Han, X. Dang, Q. Liao, Q. Peng, Q. Li and Z. Li, Chem. Commun., 2018, 54, 5598-5601.

40 M. Ikeya, G. Katada and S. Ito, Chem. Commun., 2019, 55, 12296-12299.

41 P. S. Hariharan, D. Moon and S. P. Anthony, CrystEngComm, 2017, 19, 6489-6497.

42 P. S. Hariharan, P. Gayathri, D. Moon and S. P. Anthony, ChemistrySelect, 2017, 2, 7799-7807.

43 A. Li, N. Chu, J. Liu, H. Liu, J. Wang, S. Xu, H. Cui, H. Zhang, W. Xu and Z. Ma, Mater. Chem. Front., 2019, 3, 2768-2774.

44 M. Kondo, T. Yamoto, S. Miura, M. Hashimoto, C. Kitamura and N. Kawatsuki, Chem. - Asian J., 2019, 14, 471-479.

45 P. Xue, P. Chen, J. Jia, Q. Xu, J. Sun, B. Yao, Z. Zhang and R. Lu, Chem. Commun., 2014, 50, 2569-2571.

46 Y. I. Park, O. Postupna, A. Zhugayevych, H. Shin, Y. S. Park, B. Kim, H. J. Yen, P. Cheruku, J. S. Martinez, J. W. Park, S. Tretiak and H. L. Wang, Chem. Sci., 2015, 6, 789-797.

47 S. Ito, C. Nishimoto and S. Nagai, CrystEngComm, 2019, 21, 5699-5706.

48 J. Xiong, K. Wang, Z. Yao, B. Zou, J. Xu and X. H. Bu, ACS Appl. Mater. Interfaces, 2018, 10, 5819-5827.

49 P. S. Hariharan, E. M. Mothi, D. Moon and S. P. Anthony, ACS Appl. Mater. Interfaces, 2016, 8, 33034-33042.

50 H. Shi, J. Yuan, X. Wu, X. Dong, L. Fang, Y. Miao, H. Wang and F. Cheng, New J. Chem., 2014, 38, 2368-2378. 
51 Y. Li, L. Xue, H. Xia, B. Xu, S. Wen and W. Tian, J. Polym. Sci., Part A: Polym. Chem., 2008, 46, 3970-3984.

52 P. S. Hariharan, N. S. Venkatraman, D. Moon and S. P. Anthony, J. Phys. Chem. C, 2015, 119(17), 9460.

53 A. Patra, N. Hebalkar, B. Sreedhar, M. Sarkar, A. Samanta and T. P. Radhakrishnan, Small, 2006, 2, 650-659.

54 M. Abyan, D. de Caro and S. Fery-Forgues, Langmuir, 2009, 25, 1651.

55 C. Carayon, A. Ghodbane, N. Leygue, J. Wang, N. SaffonMerceron, R. Brown and S. Fery-Forgues, ChemPhotoChem, 2019, 3, 545.

56 P. S. Hariharan, D. Moon and S. P. Anthony, J. Mater. Chem. C, 2015, 3, 8381-8388.

57 P. Gayathri, S. Karthikeyan, M. Pannipara, A. G. Al-Sehemi, D. Moon and S. P. Anthony, CrystEngComm, 2019, 21, 6604.
58 Y. Dong, B. Xu, J. Zhang, X. Tan, L. Wang, J. Chen, H. Lv, S. Wen, B. Li, L. Ye, B. Zou and W. Tian, Angew. Chem., Int. Ed., 2012, 51, 10782-10785.

59 K. Nagura, S. Saito, H. Yusa, H. Yamawaki, H. Fujihisa, H. Sato, Y. Shimoikeda and S. Yamaguchi, J. Am. Chem. Soc., 2013, 135, 10322-10325.

60 H. Yuan, K. Wang, K. Yang, B. Liu and B. Zou, J. Phys. Chem. Lett., 2014, 5, 2968-2973.

61 S. Zhang, Y. Dai, S. Luo, Y. Gao, N. Gao, K. Wang, B. Zou, B. Yang and Y. Ma, Adv. Funct. Mater., 2017, 27, 1602276.

62 Z. Wang, Z. Ma, Y. Wang, Z. Xu, Y. Luo, Y. Wei and X. Jia, Adv. Mater., 2015, 27, 6469-6474.

63 S. Lu, G. Xiao, L. Sui, T. Feng, X. Yong, S. Zhu, B. Li, Z. Liu, B. Zou, M. Jin, J. S. Tse, H. Yan and B. Yang, Angew. Chem., Int. Ed., 2017, 56, 6187-6191. 